\title{
The Development of a Virtual Community of Practices Using Electronic Mail and Communicative Genres
}

\author{
CRISTINA ZUCCHERMAGLIO \\ ALESSANDRA TALAMO \\ University of Rome (La Sapienza)
}

\begin{abstract}
This article uses the notion of genre repertoire to examine electronic-mail communication exchanged in a period of three years by an interorganizational community of software developers (727 e-mail messages in total). It analyzes the development of this virtual work community by considering the use of communicative genres with respect to (1) the resources offered by the electronic-mail system, (2) the temporal development of the project in which the participants were engaged, and (3) the developing relationship between community members. The study shows that the community organized its communicative interactions mainly as informal exchanges between peers rather than as formal exchanges that followed the structure of an interorganizational project. The messages were strongly affected by the use of a system of electronic mail and changed as the community members' relationships developed.
\end{abstract}

Keywords: communication; community; technology; genre repertoire

sociocultural approach sees writing (even the particular
form of writing required by electronic mail) as a social
activity. A writer is always a member of a community, of a set of people who, in the past and in the present, "contribute toward developing and negotiating the forms and meanings of the written language in its contexts of production and use" (Boscolo 198). Thus, an act of communication cannot be considered without also taking into account the participants in the interaction. It is the result of situated, interpretative, and constructive social work and implies a social construction of meanings (Spilka; Flower; Petraglia). Over time, individuals learn to adopt the type, or genre, of oral and written communication used by the organizational community to which they belong

Authors' Note: We thank Dorothy Winsor, Lori Peterson, and the two anonymous reviewers for their valuable comments and suggestions on earlier drafts of this article. The study has been financially supported by the research grant MURST-COFIN 2001 Virtual Communities: Collaboration Mediated by Technology.

Journal of Business and Technical Communication, Vol. 17 No. 3 July 2003 259-284

DOI: $10.1177 / 1050651903252210$

(C) 2003 Sage Publications 
(Orlikowski and Yates). From this theoretical perspective, genre refers to typical rhetorical actions that appear in a community in response to recurring situations (Miller). Thus, genres are not simply style categories but are recurring social actions that originate and give regularity to written discourses and texts (Russell).

During the past few years, research has begun to show how organizations develop communicative genres for creating the practices and knowledge they need to function (Weick). When an organization has a well-defined structure, recurring needs or problems arise, each requiring a different type of discourse. Charles Bazerman (Constructing; "Systems"), viewing written genre as a broad rhetorical strategy approved within a community, suggested that genre is associated with a set of rules that direct not only the recurring characteristics of texts but also the regularity in their production and interpretation and in the transactions between writers and readers (see also Paré and Smart).

Thus, the sociocultural notion of genre suggests that the writers' possibility of developing and using rhetorical and linguistic strategies appropriate for specific situations depends on their familiarity with the context (Miller). In fact, writing is not just a cognitive act but also, and mostly, a social practice. Therefore, learning to write adequately means learning how to participate in social and communicative interactions, adapting what one says to the requests and expectations of the receiver according to the genre repertoire, or set of communicative practices, developed and adopted in a specific community (Cherny). A community's genre repertoire is intimately tied to other aspects of its practice. According to Wanda Orlikowski and Joanne Yates, identifying the genre repertoire of a community produces information about its communicative practices: the ways in which the community organizes activities, how and why these activities change over time, and how these activities change through contact with technologically mediated communication instruments.

Each community develops specific communicative practices, both oral and written. These practices are affected by the development of the main dimensions that, according to Etienne Wenger, characterize a group as a community of practice:

1. Mutual engagement. Community members share objects of attention and organize their actions and communication around them. This dimension emphasizes the centrality of the relations and interpersonal links established between members. 
2. Joint enterprise. Members negotiate common goals through interaction, which is in turn made possible because members have common norms (ideas about what should and should not be done, what is and is not important, what can and cannot be taken for granted). This dimension emphasizes the importance of the project in which community members are mutually engaged.

3. Shared repertoire. The community possesses a set of "routines, words, instruments, ... gestures, genres, actions and concepts that [it] has produced and adopted during its existence and [that has] become part of its practices" (83).

In fact, every community has specific ways of speaking, writing, and using technological instruments and attributes particular meanings to these ways of communicating (Orr), so members form communicative genres specifically in this latter dimension of community development (Hamman; Heath and Luff; Wellman and Gulia). These genres are also affected by the communicative technologies at a community's disposal.

According to Orlikowski and Yates, two elements basically define an organization's communicative genres: communicative goal and form. The communicative goal of a genre refers to its intended purpose (e.g., informing, commenting, proposing, questioning, answering), which is constructed and recognized by the community rather than by the individual writer. The form of a genre refers to its directly observable characteristics such as structure, medium, and language. We can recognize genres within a community by the presence of one or both of these elements. For example, a business letter's goal is to document business topics, and its form is characterized by a structure that includes the sender's address, the date, and the contents and the use of formal language. The genres of a community are produced, reproduced, and changed over time according to both the changing needs of and relationships within the community. The genre repertoire may also be voluntarily or involuntarily modified when one or more genres become inactive or when new genres are added. Generally, a new genre has become part of the repertoire of a community when a union between communicative goal and form has been established (Orlikowski and Yates).

The aspects of a community's genre repertoire that are particularly relevant to this study are its composition (the set of genres constituting the repertoire) and its use (the frequency with which specific genres are used at different times by members of the community). By analyzing the composition of a repertoire, we gleaned information about 
the types of communicative activities practiced by members of a community and, therefore, about how a community organizes some of its activities. By analyzing the use of a repertoire, we discussed how these genres can change over time according to different phases in a community's development.

We suspected that some changes in the composition and use of a community's genre repertoire would result from the growing use of technologically mediated communication in work contexts (Riva and Galimberti; Smith and Kollock; Suchman). Similarly, theorists have posited a connection between genre and community that led us to suspect that the composition and use of a community's genre repertoire could also be affected by the longitudinal development of a virtual work community. Finally, we suspected that these two factors, technological mediation and community development, might interact - that is, that technological mediation might affect the practices and paths of community development, particularly in constructing a shared repertoire of communicative practices.

\section{RESEARCH AIMS}

In this study, we explore the ways that technological mediation and community development interact by examining electronic-mail communication within an interorganizational community of software developers. Our purpose for this research was to analyze the development of a virtual work community by considering the different uses of communicative genres with respect to the resources offered by the electronic-mail system, the temporal development of the project's activities, and the developing relationship between community members. Therefore, in our analysis, we focus on the following three research questions:

1. Did the electronic-mail system contribute to the construction of specific genres in the overall genre repertoire of a virtual community?

2. Did the use of the community's genre repertoire change over time as the project developed?

3. Did the use of the genre repertoire change as the relationships between community members developed and the community went through different phases?

In addition to examining these questions, we also describe the situated practices by which community members negotiated shared 
meanings and highlight the interaction between genres, instruments of technological mediation, and the phases of a community's development. Before we discuss the results of our analysis, we first explain the context and data corpus of our study as well as our method of analysis.

\section{CONTEXT AND DATA CORPUS}

Our data corpus consisted of 795 electronic-mail messages produced during about three years of work (July 1996 to April 1999) by three members of an interorganizational group involved in creating a software interface for the financial products handled by the Milan Stock Exchange. The work community was formed specifically for this project, and the members' relationships developed around and in relation to the project's evolution. We chose this specific community because it had been developed mostly via electronic-mail communication, and members rarely used other means of communicating with each other (e.g., face-to-face encounters, phone calls, formal meetings). Moreover, these three members had never worked together previously and therefore can be considered members of a community of practice that was developed and consolidated during the three years of the project.

We collected our data by collaborating with one of the members (who also gave us information about the structure and general organization of the work community) who was either a sender or a recipient of all the messages. ${ }^{1}$ The three community members we focused on were the main actors in the project: One was employed by the organization leading the project (a large Italian public company) and the other two by the organization involved in creating the product (a small Italian software development company). Their average age was 30 , and they were all male. They shared a culture of computer-engineering planning and were regular electronic-mail users. These three members were the senders (and in most cases also the recipients) of $91 \%$ of the messages produced during the three years of the project (727 messages). The remaining $9 \%$ of the messages, which we do not consider in our analysis, were produced by nine other people who played a more marginal role in the project. 


\section{METHOD OF ANALYSIS}

Drawing on the insights of Orlikowski and Yates, we categorized each of the 727 messages according to two basic elements: its communicative goal as socially recognized by community members and its formal characteristics. As a starting point, we used the categories proposed by Orlikowski and Yates: memo, note, business letter, report, proposal, and dialogue. We used slightly different definitions of these categories than Orlikowski and Yates did, adapting them both to the specificity of our data and to the communicative rules and practices specific to Italian organizational contexts. In the next section, we discuss our definitions of each category together with the categories' quantitative distribution in the composition of the genre repertoire. Two independent evaluators, whose agreement was $98 \%$, categorized the messages. They discussed the dubious categorizations until they reached an agreement. This evaluation allowed us to determine the composition of the community's genre repertoire.

To analyze the use of the genre repertoire, we also conducted a longitudinal analysis, considering the distribution of each genre during the entire work project, which we broke into 11 periods of three months each.

We carried out a qualitative analysis of the messages' form and content, rereading each message to discover emerging themes that highlight the interaction between genres, instruments of technological mediation, and phases of the community's development (Taylor). We illustrate these emerging themes through our analysis of some messages that typify the phenomena we describe (Toulmin).

\section{RESULTS}

We first discuss our results concerning the composition of the community's genre repertoire and then the various ways in which the community members used the genres in the repertoire as their project and their relationship developed.

\section{The Composition of the Genre Repertoire}

Data analysis permitted us to show that the community members recognized five genres as useful in achieving their final work goal: the note, report, dialogue, proposal, and memo (and the residual cate- 


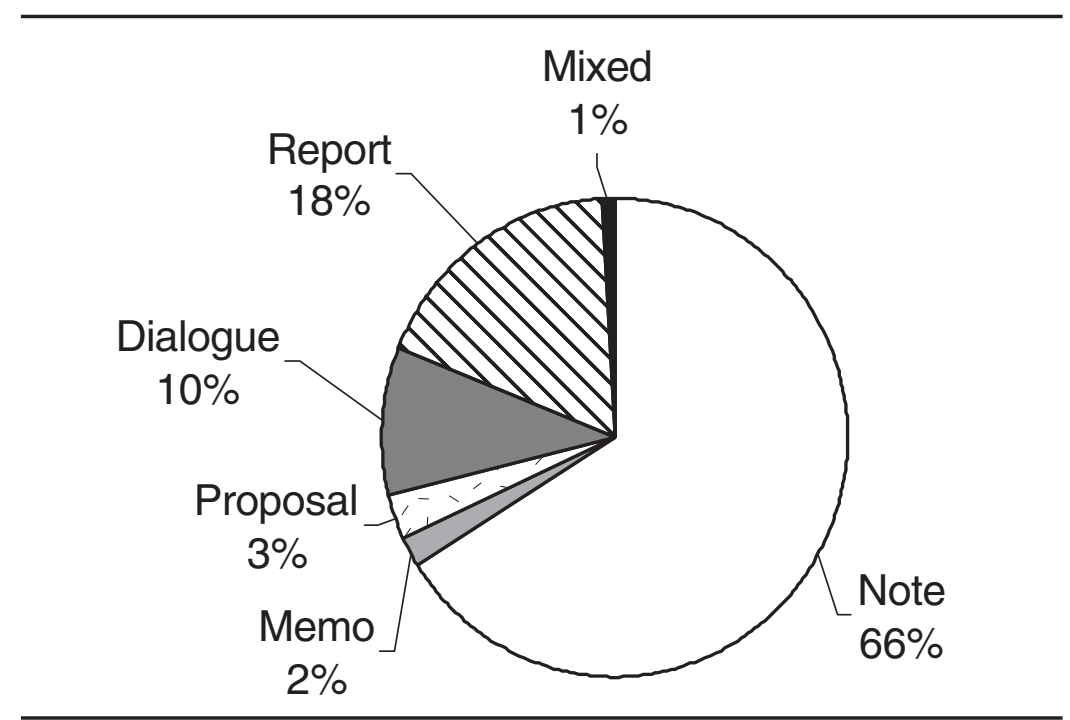

Figure 1. The Composition of Genre Repertoire

gory of mixed genre). Thus, these five genres constitute the genre repertoire of this community (see Figure 1). The following subsections describe each genre briefly and discuss its quantitative distribution in the overall genre repertoire.

Note. The most used genre in the repertoire is the note, constituting $66 \%$ of the messages exchanged. According to Orlikowski and Yates, it is the most informal written genre: "A note is used to communicate briefly, informally, and relatively personally, and is typically considered ephemeral rather than documentary" (561). We categorized as notes all messages used for brief, informal, and personal communication as well as messages containing jokes and personal news (see excerpt 1):

\section{Excerpt 1: Note $^{2}$}

To: castel@dns.WJY.com

From: Giobatta Girolfi <girolfi@XYZ.it>

Subject: various

Cc:

Bcc:

X-Attachments: 
Friday: Terrible tragedy $(18.00 \rightarrow 19.20 \rightarrow$ No taxi in Rome $\rightarrow$ home at 11:30 !!!!!)

I think it may be ok for Monday !! I'll confirm it shortly!!

Giobatta

Note messages contained in embedded text (text that had been inserted from a previous message) were also included in this communicative genre as well as messages with content that essentially coincided with the subject line, which we called a note in the subject (see excerpt 2):

\section{Excerpt 2: Note in the subject}

To: castelletto

From: Giobatta Girolfi <girolfi@XYZ.it>

Subject: I need dimensions (h, width, depth) of servers. Thanks!

Cc:

Bcc:

X-Attachments:

The use of the subject line as the message is a creative form of communication generated by this community and allowed by the electronic-mail system. In fact, all mail systems were planned to maintain the typical formal structures of official intra- and interorganizational correspondence (e.g., with lines indicating the sender, receiver, subject, etc.). However, in this case, we see a creative use of a formal structure that emphasizes the efficiency of the communication permitted by the electronic-mail system. Making the text of the communication coincide with the subject is a way of sending a message that is immediately visible to the receiver without the latter having to open the mail to read it. The fact that the message ends in the subject is indicated by the "Thanks!" (see excerpt 2), which here serves as an indicator of the communicative function of the subject line.

Report. The report genre constituted $18 \%$ of the total distribution of messages. The goal of a report is to disclose information about a certain situation; therefore, it contains an extended and analytic documentation of a topic or fact (see excerpt 3). Frequently conveyed in schematic form, a report is organized in points and uses technical and rather impersonal language. We also included messages containing attachments in the report category because the presence of an at- 
tached file enriched the message with technical, schematic, and formal elements.

Excerpt 3: Report

Date: Tue, 29 Oct 1996 15:42:37 +0100 (MET)

X-Sender: martini@mailbox.xyz.it (Unverified)

To: girolfi@xyz.it

From: Valeria MARTINI <martini@ns.xyz.it>

Subject: Updating sw funds (Maracco)

Regarding Maracco's fax of 26/10 I inform you that:

1. the sw test did not end on Saturday because there were problems with the graphics

2. We decoded Maracco's jurassic file with the utilities you sent me in file WJY

3. we thought we'd install the new sw putting only morning out of line on data not in line until a technician can check them and finally proceed to the true line up of the new maracchino. How great to return and hear "Mary had a little lamb" and Beethoven's Fifth

Bye

Valeria

Dialogue. Dialogues constituted $10 \%$ of the messages exchanged. The dialogue genre is a form of written interaction modeled on oral conversation and made possible by electronic mail's capacity to insert all or part of a preceding message (defined as embedded text) in the new text the writer is creating. This genre is characterized by the communicative goal of responding to a preceding message; thus, we categorized as dialogue only messages containing embedded text responding to proposal, report, and memo messages (see excerpt 4):

Excerpt 4: Dialogue

Date: Thu, 31 Oct 1996 07:51:42 GMT

X-Sender: castel@dns.wjy.com

To: Giobatta Girolfi < girolfi@xyz.it>

From: Dario Castelletto <castel@wjy.com>

Subject: Re: menu' principale banca

At 15.46 30/10/96 +0100, you wrote:

$>$ At 08.15 25/10/96 GMT, you wrote:

$>\mathrm{Hi}$ 
$>$ It all seems right.

>In any case for every file it's possible > to define a specific warning: right?

yes, then "actions" come all together when there is a problem on the line/

system (which has a global nature)

$>$ is everything ok with the TST and the $>$ line?

The bank has some troubles with initialising :)

The line will be definitively activated on Monday

$>$ talk to you soon

$>$ Giobatta

A nice WE (if only they could always be three days!)

dario

Dialogue via electronic mail is certainly different from dialogue that occurs face-to-face. By reporting speech (i.e., text) from a previously received message, the writer reconstructs the dialogue form in a new message. Reported speech in electronic-mail messages also seems completely different in form and in substance from that found in written language, in which such reporting is used to refer to other dialogues the writer has heard. In electronic mail, part of the text produced by others is embedded-inserted rather than referred to-into the message not only to reconstruct a dialogue form but also to indicate which part of the previously received message the writer is responding to. By selectively choosing which parts of the previous message (especially if the previous message is rather long) to insert in the response, the writer implies that the inserted text is relevant. And the fact that the inserted text is addressed directly in the response indicates its salience to the interlocutors.

Proposal. Proposals constituted 3\% of the total number of messages. The proposal genre is distinguished by its specific communicative goal: to defend a past or propose a future course of action or an idea (see excerpt 5). In this case, the goal marks the genre more than its form does. In fact, the form can take varying structural as well as linguistic characteristics. (Often this genre was included with other genres in the same message; therefore, we categorized some messages containing proposals as mixed.)

\section{Excerpt 5: Proposal}

To: castelletto

From: Giobatta Girolfi < girolfi@xyz.it>

Subject: server

Cc: 
Bcc:

X-Attachments:

I thought I'd install the servers in a rack with only one video/button/ mouse and one active switch (which makes electrical levels visible) to work on the two servers. Do you think that's ok?

Bye and thanks

Memo. Memos constituted 2\% of the message corpus. As a genre, memos are messages whose goal is to communicate brief information in a more formal manner (without embedded messages, graphics, or nonstandard elements) (see excerpt 6): As Orlikowski and Yates have explained, "A memo traditionally documents intraorganizational communication and is identified primarily by its distinct heading, rather than by a specific purpose" (554). We also categorized as memos intraorganizational messages, that is, messages sent to more than one recipient:

Excerpt 6: Memo

To: antoni, mart

From: Giobatta Girolfi < girolfi@xyz.it>

Subject: lines with Bank

Cc:

Bcc:

X-Attachments:

Hi (and Happy New Year!)

I just ordered the DCM line for the new bank system: DCM, 19.200, synchronic

The reserve line will be either a DCM or an ISDN (the bank has changed type of back up) and should arrive in the apparatus zone of the control room.

Bye

Giobatta

PS Are we ok for the expansion of 12 lines of interactive product (end of January)?

Mixed genres. A final, residual category was mixed genres (representing $1 \%$ of the total messages). These messages contained more than one genre, so they could not be categorized in only one of the previously defined genre categories (see excerpt 7). 
Excerpt 7: Mixed genre

Date: Mon, 11 Nov 1996 16:36:45 GMT

X-Sender: castel@dns.wjy.com

To: Giobatta Girolfi < girolfi@xyz.it>

From: Dario Castelletto <castel@wjy.com>

Subject: Re: documents of specific bank

At 17.02 11/11/96+0100, you wrote:

Hi!

$>$ last Friday I received the final version of the following doc:

$>$

$>$ TST Service-Interconnection of user systems

>- Specifics of applied flows v.5.0, 21/10/96

>- Functional specifics v.1.5, 21/10/96

>- Technical specifics v.1.2, 19/05/95

$>$

$>$ do you also have them?

$>$ Bye - giobatta

Yes - Thanks - We also received them.

I take the opportunity to present you with two problems:

*definition nick-name

*change of titles selection of one index

These changes, operable through more or less complicated list-box windows, will finally have an impact on the tables of the $\mathrm{db}$ of the server that are used for the display in real time of the information produced. Due to obvious considerations of concurrent access to one table and various look-up problems, the preceding two points involve important considerations.

Since a change in titles selection provokes the re-compacting of the lookup table (long operation), when do you think it can phase? More linear solution to not "interrupt" the transmission is to make changes at the end of the transmission (before back-up): what do you think?

bye - dario

P.S. How did the new kitchen go?

This message simultaneously contains the note genre, in the answer to another note and in the postscript; the memo genre, in the technical discussion; and the proposal genre, in the proposed solution to a problem.

The composition of the genre repertoire shows that the community used five genres to develop the work project and to reach its work objectives. Several genres, such as notes, played a broad communicative role; others, such as memos and proposals, constituted marginal percentages of the community's total electronic-mail communication. 
Moreover, the electronic-mail system itself contributed to the construction of specific genres, such as dialogues and notes in the subject. This genre distribution-especially the prevalence of the note messages and the absence of other genres, such as business lettersindicates that the community organized its communicative practices as informal peer interactions rather than formal interorganizational exchanges. Thus, the composition of the genre repertoire indicates the kind of relationship that existed between community members. Moreover, the prevalence of notes and dialogues showed that the members cooperatively defined both the activities needed to develop the product and the means to their practical realization. Hence, the repertoire was also shaped by the project in which the community members were mutually engaged. The presence of the report genre demonstrated that the members could also communicate in more formal and analytic ways when necessary: In this case, an organizational rule that work should sometimes be documented more formally occasionally obliged members to produce a formal report, a genre that was also more suitable for communicating with those outside of the community. However, our analysis thus far did not allow us to determine if this repertoire composition was stable throughout the development of the project and the community. In the next section, we address this issue.

\section{The Use of the Genre Repertoire}

To account for the development of the community and for the evolution of its communicative practices, we analyzed the evolution of the genre repertoire during the three years of the project. We hypothesized that use of the genre repertoire changed as project activities and relationships between members developed and as the community went through various phases.

The institution of an initial genre repertoire is typically a stabilizing force. The members of a new community generally tend to import communicative practices from their preceding work contexts, thus preserving familiar norms and practices (Wenger). However, deliberate or involuntary changes in the use or composition of genre repertoires can always occur in such situations. In fact, these variations may be responses to changes both in the development of the community and in the activities, phases, and means of communication used throughout the work project. In our data, variations occurred not in the composition of the genre repertoire (i.e., it always consisted of the 


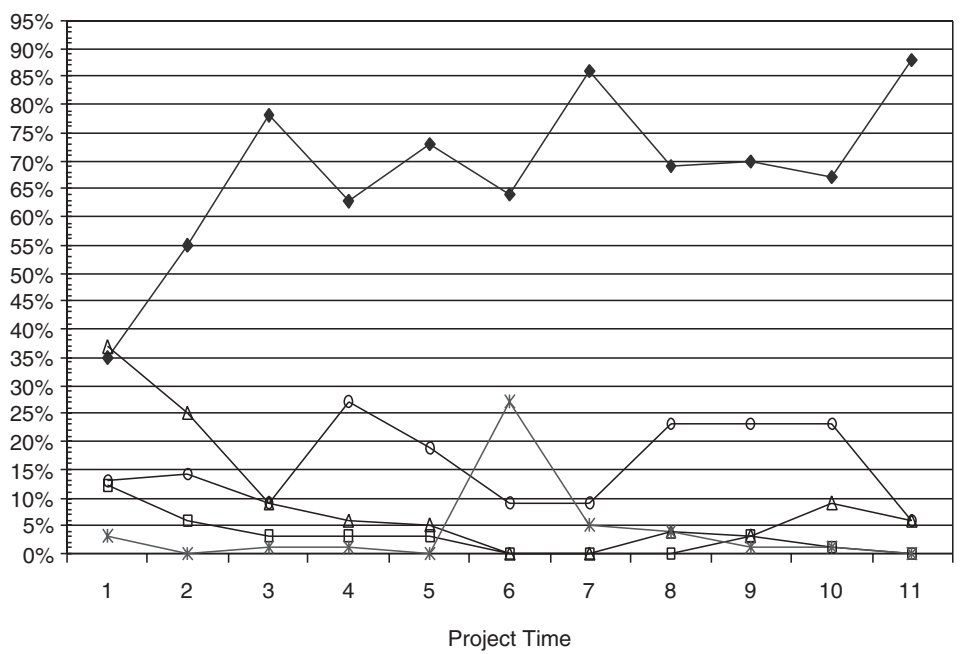

- NOTE $\triangle$ DIALOGUE- - REPORT- $\square-P R O P O S A L ~ *$ MEMO

Figure 2. Use of the Genre Repertoire

NOTE: We divided the project time into 11 three-month periods.

same five genres) but in the use, more or less frequent, of each communication genre. The distribution of the genres used by the community showed several peculiarities linked both to the specific project activities and to the particular stages of community development. The graph in Figure 2 shows the percentage of messages constituted by each genre throughout the 11 three-month periods of the project.

Apart from the first period, community members always used the note genre most. Moreover, the graph in Figure 2 shows unusually frequent use of this genre in periods 3 (78\% of total messages), 7 (86\% of total messages), and 11 (86\% of total messages). By examining the notes exchanged during these periods, we were able to determine the kind of communicative needs the genre was most useful in meeting. During period 3 (January-March 1997), community members verified a series of product anomalies and tested the product. These events required a lively exchange of notes between members that facilitated asking questions and providing answers in order to resolve problems and make decisions.

In period 7 (January-March 1998), members tested the product for the final time before its installation. The use of notes kept members 
up-to-date regarding test results and necessary changes in the product. Members installed the product in period 11 (January-April 1999). At that time, communicating through notes (86\% of total messages) enabled members to communicate problems and imperfections, on one side of the exchange, and provide the right solutions, on the other. Notes were used infrequently only at the beginning of the project: In period 1 (July-September 1996), they constitute only $35 \%$ of the total messages. This infrequent usage probably indicates that, in the first phase of community development, an informal genre such as noteswhich presupposes a shared context of interaction-is not so appropriate for members who have not yet had a chance to share many interactions. Thus, these results show that the note genre characterized the communicative style of this community but only after a certain phase of community development: In January 1997, after six months of project work and community development, $78 \%$ of the total messages of the community were notes.

Reports were frequently used in period 4 ( $27 \%$ of total messages) and in periods 8 through 10 (23\% of total messages in each period). In period 4 (April-June 1997), the reports primarily consisted of files containing technical specifications about the product being developed. In periods 8, 9, and 10 (April-December 1998), the reports primarily provided information about the functioning of the product to be installed. From this use, we can ascertain that the report was primarily useful for communicating technical data and, thus, was particularly used when members needed to send new versions or technical modifications of the product.

The frequencies of both the proposal and dialogue genres were at their peak in period 1 ( $12 \%$ and $37 \%$ of total messages, respectively). Dialogue also remained a frequently used genre in period 2 (25\% of total messages).

The initial high incidence of dialogue messages was partially due to the high number of micro decisions members needed to make about specific aspects of the software product they were dealing with (see excerpt 4): Members used the dialogue genre for sharing their knowledge about times, paths, and rules for accomplishing common work. Moreover, dialogue messages were initially necessary for responding to the large number of proposals for defining the computer product. These proposals were common at the beginning of the project, when members needed to share courses of action and ways of carrying out the project. Also, the greater formality of proposals, as compared to notes, made that genre more useful during the early 
development of the virtual community. As the relationship between the members grew closer, especially after they had had two face-toface meetings, this genre was replaced by the more informal notes. However, the limited use of the dialogue genre throughout the project is difficult to explain. This genre was produced by the use of an electronic-mail system and seemed particularly suited for sustaining the growing informal relationship between community members. Perhaps notes substituted for dialogues in this community's genre repertoire, as the inverse relationship between the use of note messages and the use of dialogue messages would indicate.

The use of the memo genre was always limited (only 11 memo messages were sent during the entire project) and for that reason was also rather stable over time. The exception was in period 6 (OctoberDecember 1997), when memo messages represented $27 \%$ of the total messages, but this percentage represented only three memo messages. In this period, few messages about this project were sent (only 11 messages in three months) because members were waiting for decisions and information from the Milan Stock Exchange. Members used the three memo messages to document the project's development phase to organizational members outside of their community.

These results suggest a relationship between the use of the genre repertoire and phases in the development of the project and the community. In particular, the overall use of each genre (e.g., the increased use of notes over the whole project) seemed connected with the developing relationship between community members whereas the relative use of each genre in different periods (e.g., the spikes in the use of notes during periods 3,7 , and 11) seemed more connected to specific project activities. To explore these relationships in more detail, we present the results of our qualitative analysis of messages.

\section{The Interaction between Genres, Instruments of Technological Mediation, and the Development of the Community}

The results we have just discussed indicate that the genre repertoire's use depended on several specific characteristics of the instruments of technological mediation as well as on the development phases of the community and of the project.

Aspects of this repertoire were concretely negotiated through the communicative exchanges that constituted the structure in which the work community developed. This section describes the ways in which members negotiated some basic aspects of their work function- 
ing and coconstructed the shared repertoire of the community that was being established and also highlights the interaction between genres, instruments of technological mediation, and the development of the community. Aspects of the shared repertoire that were negotiated included the level of formality, content of the messages, communicative rules of the project, development of vocabulary and genre, and tolerance for errors.

Level of formality. We were able to observe how interacting members proceeded in their interpersonal relations. The first messages exchanged were formal (see also Zucchermaglio); the members, Dario and Giobatta, used a professional linguistic register in the thirdperson singular and signed with both first and last names (see excerpt 8).

\section{Excerpt 8}

To: Girolfi@XYZ.it

Subject: look-up table GSP

Date: Wed, 10 Jul 96 11:23:20 METDST

I received the mail with the tedeo text attributes, which was very useful. Thanks.

I would be very grateful if you could send me some information, particularly regarding point 1 .

Regards,

Dario Castelletto

After Dario and Giobatta met in person at a meeting of the planning group, they adopted a more informal communicative genre, one that was more adapted to the activity they were carrying out and the relationship that was being defined. ${ }^{3}$ In their first messages, Dario and Giobatta spoke only of facts and problems pertaining to the project. They also used the note in the subject genre as a condensed method of communicating facts.

Content of the messages. In addition to adopting a more informal register, Dario and Giobatta also shifted the topics they wrote about as their relationship developed. In the messages they exchanged before they met in person, they referred exclusively to work aspects and problems. Later, the two members included in their messages refer- 
ences related to personal events, such as family commitments, health, and vacations (see excerpt 9).

\section{Excerpt 9}

Date: Fri Mar 14 12:57:30 1997

To: Dario Castelletto < castel@wjy.com>

From: Giobatta Girolfi <girolfi@XYZ.it>

Subject: Re: (perhaps) I can manage to send/receive electronic mail!!

Cc:

Bcc:

X-Attachments:

I came back from Brussels today- I'm sick: I ate mussels and oysters from the North Sea and fear I did something stupid. (Seriously)

If I don't go home, I'll call you later.

Bye

Giobatta

The two members increasingly used notes in their informal exchanges, to the point of it becoming a rule. Its transgression was announced and disputed (see excerpt 10).

Excerpt 10

Date: Wed, 8 Jan 1997 08:56:02 GMT

X-Sender: castel@dns.WJY.com

To: Girolfi@XYZ.it

From: Dario Castelletto <castel@wjy.com>

Subject: line, funding, etc.

I'm starting to design the characteristics of Tedeo funding. Could you tell me when the funds line is interrogated (once, twice a day?)

Regarding the temporary line, if you let me know soon if everything is ready for the continuation of the contract, I can phone Bagozza to let you know the date (to write on the request) for passage to the production area.

Shortly I must send you a "very formal" mail (that *Cc likes) summarising yesterday's telephone conversation-sorry.

Bye and thanks

Dario

Dario's need to send "a very formal mail," which is quite different from the informal note genre shared in the community, mirrors the 
need to also account for a different use of a communicative genre at the organizational level (i.e., outside the community).

Communicative rules of the project. Community members negotiated not only how they would communicate with each other but also how the various pieces of software they were developing would communicate with each other and with the software's users. The time members spent sharing communicative rules regarding technical aspects of the software product was also important to the process of coconstructing a shared repertoire. This sharing of communicative rules can be seen in Giobatta's message describing the formal characteristics required for the Tedeo system and on which the entire project must be constructed (see excerpt 11).

Excerpt 11

Tue Jul 09 16:36:29 1996

To: castel@WJY.com

From: Giobatta Girolfi < girolfi@XYZ.it>

Subject: Tedeo text attributes

Cc:

Bcc:

X-Attachments:

The Tedeo page is composed of 24 lines $\times 40$ columns.

The attributes (colour, blinking, largest dimension) have effect from the position after the one they are at until the end of the line. At the beginning of the line the attributes are re-set to default that is:

- black background

- text modality

- white colour

- no blinking

The Tedeo control characters can be transmitted through the corresponding hexadecimal code or through the escape sequence $/ \mathrm{hh}$. For example the red code character is " $/ 01$ or $0 \times 01$.

I hope it's clear.

Development of vocabulary and genre. In addition, the members gradually introduced terms and symbols with special meanings for them. The following messages (see excerpts 12 and 13) are examples of how, through negotiation, members attributed an original meaning to a mathematic symbol: Its shared meaning was increasingly developed 
during the interaction in order to personalize reciprocal greetings. For instance, Giobatta introduced ciao++ as a sort of extra ciao, implicitly referring to the members' understanding of the technical meaning of the + symbol commonly used to increase that which precedes it in a mathematical formula (e.g., $\mathrm{N}+1$ ). This nonstandard use of the + symbol forces Dario (see excerpt 13) to ask for confirmation of his interpretation of it as a double ciao ("ciao+=2?").

Excerpt 12

To: castelletto

From: Giobatta Girolfi <girolfi@xyzai.it>

Subject: ver 2.0

Cc:

Bcc:

X-Attachments:

Clock: Which one do you prefer?

the rest is ok

ciao++

Excerpt 13

Date: Wed, 18 Sep 1996 10:58:27 GMT

X-Sender: castel@dnswjy.com

To: gidrlfi@xyz.it

From: Dario Castelletto <castel@wjy.com>

Subject: automatic colours on table

X-Attachments: C: \DArio \PRJ $\backslash X Y Z \backslash L A Y-O U T . Z I P$;

your ciao++ puzzled me,

does it mean ciao $+=2$ ?

Dario Castelletto

During the project, members also progressively coconstructed shared communicative norms that took advantage of the peculiarities and limits of the telecommunication system. The project members, all regular users of electronic mail who belonged to the same computerengineering community, already had rules for using electronic mail. Members' tacit and widely shared knowledge of norms of interaction was then reinforced and enriched as the community developed, such as in their coconstruction of the note in the subject genre, which took advantage also of the peculiarities offered by the electronic-mail system. The negotiation of a shared repertoire also occurred with the coconstruction of linguistic games that took advantage of some of the peculiarities of written communication such as the use of emoticons, 
the little faces that are inserted beside messages (particularly in notes) to provide an emotional connotation (see excerpt 14).

\section{Excerpt 14}

Thu Sep 12 11:10:53 1996

To: Dario Castelletto <castel@wjy.com>

From: Giobatta Girolfi < girolfi@XYZ.it>

Subject: Re: welcome back

Cc:

Bcc:

X-Attachments:

what are you doing, checking me?

Bye, I'll talk to you soon

::-) (I wear glasses)

In addition, the members' joint vocabulary was characterized by the use of new terms or computer jargon derived from the following English terms (not commonly used in Italian): check, vampire, feedback, flag, zip (see excerpt 15).

\section{Excerpt 15}

To: Girolfi@XYZ.it

From: Dario Castelletto <castel@wjy.com>

Subject: fresh zipped specifics

X-Attachments: C: \DARIO \XYZ $\backslash D O C S \backslash X Y Z . Z I P$;

i re-zipped everything.

bye - dario

As terms in this specific jargon became known by the computerengineering community, members gradually began to use the jargon regularly in their interactions with each other. We interpret this shared jargon as an additional marker of their growing informal relationship.

Tolerance for errors. Some characteristics of the written texts the community produced seemed to depend even more directly on an interaction between phases of community development and typical characteristics of technologically mediated communication. For example, as the relationship between the members developed, they be- 
came more tolerant of both orthographic and syntactic errors in communication mediated by electronic mail than they would be of such errors in traditional written language. This tolerance seemed to be another marker of the growing informality that characterized the relationship between community members. In fact, when individuals outside the community became involved in the communication, the language returned to that of traditional interorganizational communication, in which textual correctness and formality are valued. This shift in genres and in communicative modalities marked the fact that over time, members considered themselves as a separate community. For this reason, they marked and characterized their communication with others outside their community as clearly different (see excerpt 16).

\section{Excerpt 16}

To: girolfi@XYZ.it, “Rena”<tedeo@XYZ.it>

From: Dario Castelletto <castel@wjy.com>

Subject: Tedeo Market Macro Functioning

X-Attachments: C: $\backslash D A R I O \backslash P R J \backslash X Y Z \backslash F U N Z . D O C$;

I am sending you all of the functioning I defined for the tedeo funds market applied windows. They permit the definition of a unique graphic interface for the various users who will have present/validated/invalidated the various controls/menu

I await your advice for proceeding to reorganization of graphic windows.

Regards,

Dario Castelletto

This message confirmed that the community negotiated and developed an informal register for dealing with specific work activities and for sustaining the informal relationships members had developed during the project. The use of notes, for example, was not indiscriminate; this genre was never used to communicate to those outside the group. Even when the aim of a message was the same as that of a note, the genre any member used varied as a function of the relationship between sender and receiver. These results suggest that use of a genre repertoire is affected by the peripheral-central dimension of community membership. The qualitative analysis shows that members chose to use formal or informal genres depending on whether they were writing to internal (i.e., central) community members or external (i.e., peripheral) organizational ones. Future research is needed to analyze the influence of different receivers on the composi- 
tion and use (and content) of the genre repertoires of other virtual communities.

Our results show that an electronic-mail system was able to sustain the negotiation of some basic work functions and the coconstruction of a shared repertoire of the community, even if a not insignificant role was played by the first face-to-face meeting. Compared with paths of community development in face-to-face situations, as in meetings (see, e.g., Zucchermaglio and Talamo; Fasulo and Zucchermaglio), electronic mail seemed to allow a more rapid community development, particularly in the coconstruction of a shared repertoire dimension. Future research is needed to analyze the development of communities mediated by other types of electronic or technological systems (see Talamo, Zucchermaglio, and Ligorio).

\section{CONCLUSIONS}

The two dimensions central to this analysis, that is, the composition of the repertoire and its use, contributed to reveal several basic aspects of the work community's development of communicative practices. The composition of the repertoire included five different genres that community members used to reach their work objectives (note, proposal, memo, report, and dialogue). The prevalence of note messages, together with the absence of other genres (such as business letters), indicates the prevalence of an informal communicative and work style. Nevertheless, the presence of genres such as the report or proposal indicates that members could also communicate (especially with the outside of the community) following more formal and organizational rules. Moreover, the electronic-mail system contributed to the construction of specific genres, such as dialogue and note in the subject.

The longitudinal analysis of the use of the genre repertoire shows that use depends on both specific project activities and phases of community development. The distribution of the messages shows how the community made different use of genres over time. Occasional spikes in the use of certain genres were linked to the different project activities members were dealing with whereas the overall development of each genre's use was connected with the growing and developing relationship between community members. In particular, a rapid shift can be observed toward the production of genres (such as note messages) more consonant in terms of goals and form with the 
informality characterizing the relationships between members over time. This result leads us to believe that the informality characteristic of electronic-mail communication that is widely documented in the literature may be a dimension that is negotiated and coconstructed, even rapidly, by members during interaction. However, informality may not necessarily be present in the initial communicative exchanges between the members of a new community. The coconstruction of this informality was very rapid in our virtual community (taking about six months). Further research is needed to analyze if initial formality followed by negotiated informality is also characteristic of other virtual communities, with more members and with more differentiated organizational and professional identities.

Qualitative examination of the messages revealed that some aspects of the communication were determined by specific characteristics of the electronic-mail communication system. Some genres (such as note in the subject or dialogue) and also some formal characteristics of messages (such as the use of emoticons) show how both formal and informal communications benefit from the expressive capacities members acquired through the resources offered by the system of mediation.

Another important result concerns the ways in which members communicated with outsiders. The increased formality of these messages marked the fact that the community recognized itself as a community and recognized those who were not part of the community as different. It also showed that the communicative genre repertoire was a basic instrument for moving with competence within communicative and organizational practices (including technologically mediated ones) that characterized the boundaries between communities and the more or less central community membership of sender and receiver.

Our analysis was limited to one small virtual community; nevertheless, results show the use of the notion of genre repertoire for the description of communicative practices (including technologically mediated ones) that characterize the growth and development of work communities.

\section{NOTES}

1. The participants involved in this study were all informed about our research aims and methodology and the privacy rules according to the Ethical Rules of the Italian 
Association of Psychology. All personal names, institutional names, and e-mail addresses are fictitious.

2. All the messages were originally written in Italian. We present here their translation as literally as possible.

3. Despite the flexibility of electronic mail and the growing informality in communication as the relationship between community members developed, telephone conversations and the two face-to-face meetings played an important role in the development of the shared repertoire of the community.

\section{REFERENCES}

Bazerman, Charles. Constructing Experience. Carbondale: Southern Illinois University Press, 1994.

_- "Systems of Genres and the Enactment of Social Intentions." Genre and the New Rhetoric. Ed. Aviva Freedman and Peter Medway. Bristol, UK: Taylor \& Francis, 1994.

Boscolo, Piero. "Scrivere testi" [Writing Texts]. Manuale di psicologia dell'educazione. Ed. Clotilde Pontecorvo. Bologna, It.: Il Mulino, 1999. 195-220.

Cherny, Lynn. Conversation and Community: Chat in a Virtual World. Stanford, CA: Stanford University, Center for the Study of Language and Information, 1999.

Fasulo, Alessandra, and Cristina Zucchermaglio. "Organizational Stances: SelfReference in Work's Meeting Talk." Journal of Pragmatics 34 (2002): 1119-44.

Flower, Linda. The Construction of Negotiated Meaning: A Social Cognitive Theory of Writing. Carbondale: Southern Illinois University Press, 1994.

Hamman, Robin B. "Computer Networks Linking Network Communities: Effects of AOL Use upon Pre-Existing Communities." Exploring Cybersociety Conference. London. July 1999. Retrieved from http:/ / socio.demon.co.uk/cybersociety

Heath, Christian C., and Paul K. Luff. Technology in Action. Cambridge, MA: Cambridge University Press, 2000.

Miller, Carolyn R. “Genre as Social Action.” Quarterly Journal of Speech 70 (1984): 151-67.

Orlikowski, Wanda J., and Joanne A. Yates. "Genre Repertoire: The Structuring of Communicative Practices in Organizations." Administrative Science Quarterly 39 (1994): 541-74.

Orr, Julian. "Ethnography and Organizational Learning: In Pursuit of Learning at Work." Learning, Organizations and Technology Change. Ed. Cristina Zucchermaglio, Sebastiano Bagnara, and Susan Stucky. New York: Springer Verlag, 1995.

Paré, Anthony, and Graham Smart. "Observing Genre in Action: Towards a Research Methodology." Genre and the New Rhetoric. Ed. Aviva Freedman and Peter Medway. Bristol, UK: Taylor \& Francis, 1994. 89-107.

Petraglia, Joseph, ed. Reconceiving Writing, Rethinking Writing Instruction. Mahwah, NJ: Lawrence Erlbaum, 1995.

Riva, Giuseppe, and Carlo Galimberti. "Computer-Mediated Communication: Identity and Social Interaction in an Electronic Environment." Genetic, Social and General Psychology Monographs 124 (1998): 434-64.

Russell, David R. "Writing and Genre in Higher Education and Workplaces: A Review of Studies That Use Cultural-Historical Activity Theory." Mind, Culture and Activity: An International Journal 4 (1997): 224-37. 
Smith, Marc A., and Peter Kollock, eds. Communities in Cyberspace. London: Routledge, 1999.

Spilka, Rachel. Writing in the Workplace: New Research Perspectives. Carbondale: Southern Illinois University Press, 1993.

Suchman, Lucy. "Constituting Shared Workspaces." Cognition and Communication at Work. Ed. Yrjo Engestrom and David Middleton. Cambridge, MA: Cambridge University Press, 1996.

Talamo, Alessandra, Cristina Zucchermaglio, and Beatrice Ligorio. "Communities' Development in CVEs and Sustaining Functions of On-Line Tutorship." Cyberpsychology: Mind, Identity and Society in the Internet Age. Ed. Giuseppe Riva and Carlo Galimberti. Amsterdam: IOS books, 2001. 186-205.

Taylor, Tina L. "Life in Virtual Worlds: Plural Existence, Multimodalities, and Other Online Research Challenges." American Behavioural Scientist 43 (1999): 436-49.

Toulmin, Stephen. "Concluding Methodological Reflections: Elitism and Democracy among the Sciences." Beyond Theory: Changing Organizations through Participation. Ed. Stephen Toulmin and Bjorn Gustavsen. Amsterdam: Benjamins, 1996. 203-25.

Weick, Karl E. "Theorizing about Organizational Communication." Handbook of Organizational Communication. Ed. Fredric M. Jablin, Linda L. Putnam, Kevin H. Roberts, and Lan W. Porter. Newbury Park, CA: Sage, 1987. 97-112.

Wellman, Barry, and Milena Gulia. "Virtual Communities as Communities: Net Surfers Don't Ride Alone." Communities in Cyberspace. Ed. Mark A. Smith and Peter Kollock. London: Routledge, 1999. 167-94.

Wenger, Etienne. Communities of Practice: Learning, Meaning and Identity. Cambridge, MA: Cambridge University Press, 1998.

Zucchermaglio, Cristina. "Gruppi di lavoro: tecnologie, pratiche sociali e negoziazione" [Workgroups: Technology, Social Practices and Negotation]. Ergonomia. Le tecnologie nel contesto sociale. Ed. G. Mantovani. Bologna, It.: Il Mulino, 2000. 181-202.

Zucchermaglio, Cristina, and Alessandra Talamo. "Identità sociale e piccolo gruppo" [Social Identity in the Small Group]. Giornale Italiano di Psicologia 27.3 (2000): 57-86.

Cristina Zucchermaglio is a full professor of social psychology at the University of Rome (La Sapienza). Her research topics include practices of written communication, social interaction and discursive practice, computer-mediated practices, and small group development and identity negotiation through interactive discourse. She has edited and coedited numerous books and chapters and has published more than 60 articles in national and international journals. She may be reached by e-mail at Cristina. Zucchermaglio@uniroma1.it.

Alessandra Talamo is a contract researcher at the Department of Social and Developmental Psychology of the University of Rome (La Sapienza). Her research activities focus on the study of cooperation and collaboration in work groups. The theoretical background, which all her research activities move from, is that of cultural psychology and activity theory. She may be reached by e-mail at Alessandra.Talamo@uniroma1.it. 